\title{
Comemorações num (in)certo eldorado: etnicidade e festas no sul do Brasil (1980- 2002)
}

\author{
Celebrations in (un)certain Eldorado: ethnicity and festivities \\ in Southern Brazil (1980-2002)
}

\author{
Emerson César Campos ${ }^{1}$
}

\section{RESUMO}

Existem muitas festas, nacionalmente conhecidas, desde o Sul do Brasil, que celebram motivações primeiras, como etnicidade e lugares de memória. Neste contexto, a paisagem catarinense é certamente um grande campo de análise. No presente artigo são apresentadas reflexões sobre as construções dos sentidos étnicos que se estendem sobre as celebrações coletivas postas em Santa Catarina, desde a análise dos festejos do Centenário da Colonização e da criação da Festa das Etnias em Criciúma, sul do estado, cidade e região, que até a década de 1990 celebrou as conquistas e derrotas engendradas por ação extrativista mineral, e que a fez ser reconhecida no Brasil como a capital brasileira do carvão. Esta narrativa foi possível graças ao cruzamento de fontes de diferentes tipologias: orais e documentos oficiais e escritos sugeridos pela historiografia correlata ao tema. Desta forma, foi possível perceber que as celebrações festivas fundam e transformam a paisagem sociocultural catarinense.

Palavras-chave: Cidade; Comemorações; Festas; Etnicidade; Cultura.

\section{ABSTRACT}

There are many festivities known nationally, all along from Southern Brazil, which seek to celebrate former motivations such as ethnicity and 'memory sites'. Thus, Santa Catarina's landscape is certainly a

1 Prof. Dr. Emerson César de Campos. Professor Associado do Departamento e Programa de Pós Graduação em História da Universidade do Estado de Santa Catarina - UDESC. Possui graduação em História pela Universidade do Estado de Santa Catarina (1997), mestrado em História pela Universidade Federal de Santa Catarina (1999) e doutorado em História pela Universidade Federal de Santa Catarina (2003). Também é graduado em Engenharia Civil pela Universidade Federal de Santa Catarina (1995). Tem experiência na área de História, com ênfase em História Cultural, atuando principalmente nos seguintes temas: Cidades, Migrações, Teoria da História e Imagens e Expressões Gráficas e Humor como Fontes à História. Atualmente (2013) ocupa a Função de Diretor Geral do Centro de Ciências Humanas e da Educação - FAED / UDESC. 
big and rich field for analysis. This article presents many reflections on the meanings of ethnic constructions that are expanded to the collective celebrations that can be seen in Santa Catarina, from analysis of the celebrations of the centenary of Colonization and the creation of the Ethnic Groups Festival in Criciúma, South State, city and region that until the 1990s celebrated the victories and defeats action engendered by mining, and that has to be recognized in Brazil as the Brazilian Capital of Charcoal. This narrative was made possible by the crossing of different types of sources: oral sources as well as official documents and writings suggested by the historiography related to the theme. Therefore, it was possible to see that the festive celebrations merge and transform the socio-cultural landscape of Santa Catarina.

Keyword: City; Celebrations; Festivities; Ethnicity; Culture.

Há uma produção recente, consistente e já um tanto amadurecida, em nosso país, que trata da realização de festas e outras celebrações (JANCSÓ; KANTOR , 2001). Também já foram abordados pela historiografia alguns festejos e comemorações catarinenses que quase sempre "vêm à baila" nacionalmente. Flores, por exemplo, trata da Farra do Boi (1997b) e da Oktoberfest (1997a?). Neste artigo, busco discutir, nas limitações próprias a texto dessa monta, uma celebração específica e que considero fundante: as comemorações alusivas ao centenário da colonização europeia no sul do Brasil e os processos de etnicização engendrados na região. São conhecidas as celebrações do Centenário da Colonização italiana em Caxias do Sul (RS), em 1990, em Rodeio (SC), em 1975, ou mesmo da alemã, em Joinville (SC), em 1950. Nesta seara, tomo como objeto a realidade sociocultural vivida na cidade de Criciúma, localizada no sul de Santa Catarina, durante a celebração e os festejos da colonização daquele município, ocorridos em 1980, e que, sob vários aspectos, podem elucidar muito da inventividade e da criação dos liames sociais que constroem nossa realidade e reverberam em nosso tempo presente.

Em apresentação bastante rasa, pode-se dizer que a Capital Brasileira do Carvão teve sua história de tal forma imbricada, sobreposta, no que nela se convencionou chamar de pedra fundamental do progresso, o carvão, cuja construção parecia inviável fora desta base. $\mathrm{O}$ fluxo de pessoas para e pela cidade, vindas de diversas regiões do estado e do País, foi constante e se intensificou entre 1950 e 1980, época do eldorado catarinense. Entretanto, em 1987, após uma redução considerável dos subsídios, que por mais de 40 anos haviam sido fornecidos pelo governo federal à indústria extrativa do carvão mineral, o setor se retraiu abruptamente, provocando desemprego e gerando uma crise social de grandes proporções. Após um período de intensas reivindicações e lutas, promovidas por movimentos sociais, sindicatos, organizações de bairro, imprensa e pelo próprio empresariado local, Criciúma deixou de ser divulgada como a Capital Brasileira do Carvão $0^{2}$ Embora hoje (2011) não mais se

\footnotetext{
${ }^{2}$ Em livreto editado pela prefeitura de Criciúma, datado de janeiro de 1986, o ex-prefeito e ex-vice-governador de Santa Catarina, José Augusto Hülse, escreve: "Instado a dar nome a um documentário cinematográfico produzido sobre a cidade, o então prefeito Addo Faraco, em 1948, o chamou de Criciúma: Capital do Carvão. Naquele momento o título foi criado".
} 
explore o carvão em seu território, nela tem sede a administração de algumas empresas carboníferas que operam na região em razão da capacidade logística oferecida pela cidade. Cabe perceber ainda que, apesar de esforços como os colocados, não parece possível que, quase por decreto, se decida pela morte de uma cultura. Lembrando o que já disse Paul Veyene (1983, p. 55), uma cultura está bem morta quando a defendem em vez de inventá-la. Assim, espero aos poucos apresentar, neste artigo, os processos deslizantes de significação colocados em Criciúma por ocasião dos festejos do Centenário da Colonização da cidade na virada de década de 1970 para a de 1980.

Para que se tenha uma ideia mais elaborada da composição da cidade, assumo índices básicos sobre ela. Sua população era de 99.735 habitantes em 1980; o município contava com 11 empresas carboníferas instaladas em seu território; mais de $50 \%$ da população economicamente ativa estava vinculada à extração do carvão (IBGE). Outra referência para deixar claras as transformações ocorridas na cidade em uma década (1991) é a de que Criciúma apresentava uma população de 146.162 habitantes, com apenas quatro empresas carboníferas em funcionamento. Em 2000, com apenas uma empresa carbonífera ativa no município, sua população tinha atingido 170.274 habitantes, dos quais 152.903 residentes na área urbana e 17.371, na área rural.

Lugares muitos bem marcados, como a "cultura do carvão" e os usos da etnicidade, podem ser vistos de modos relacionais, imbricados e produtores de liames ou urdiduras. Evidentemente, histórias múltiplas sobre Criciúma foram e vêm sendo produzidas. $\mathrm{O}$ sentido múltiplo não é necessariamente diferente. Ao contrário, ele pode, e os exemplos são inúmeros, ser uma poderosa ferramenta ratificadora de lugares comuns. Embora de agradável leitura e, por vezes, bem-humorada, a historiografia criciumense, ao menos aquela realizada até a década de 1980 , se compõe e se constrói através do trabalho desenvolvido pelos que convencionalmente se podem chamar oficialistas-memorialistas ${ }^{3}$. Há nela um sentido épico e reificador, sendo necessário fazê-la produzir sentidos, e não apenas lágrimas e risos, na expressão utilizada em 1978 pelo então prefeito da cidade, Altair Guidi, na festa de recepção ao cônsul italiano, por ocasião dos antecipados festejos do centenário da colonização de Criciúma, realizado em 1980. É mister, numa espécie de antiafinidade eletiva, acionar um diálogo que possibilite, ao mesmo tempo, uma leitura compreensiva e, paradoxalmente, dissonante.

Entre tantas aberturas possíveis para se entrar em Criciúma, duas particularmente se mostram com maior imponência: a cultura do carvão e o que, na ausência de uma

\footnotetext{
${ }^{3}$ Entendendo por memorialistas os que Peter Burke (1992) chamou de "antiquários". Aplicado ao estudo relativo à cidade de Criciúma, memorialistas seriam aqueles que, num primeiro momento, cuidaram de coletar fontes, reunir documentos e realizar uma história possível sobre a cidade. Tal preocupação se mostra mais efetiva a partir da década de 1970. Oficialistas seriam os profissionais que, próximos das produções dos memorialistas, coletam dados e organizam escritos, prioritariamente com base em documentos escritos, pouco considerando contribuições outras que possam ser fornecidas pela história oral e pela memória das pessoas.
} 
denominação mais adequada, chamo de "mercado étnico". Num trabalho muito bem preparado, (TEIXEIRA, 1996, p. 34) aponta:

[...] se é válido pensar a cidade a partir do reconhecimento social dos mineiros e de sua força histórica e simbólica, reduzi-la a isto seria uma mistificação, uma ideologização da história de Criciúma, da mesma forma como faz a historiografia oficial ao reduzir e reproduzir a história da cidade pelo viés da colonização, isto é, a partir das diferentes etnias que colonizaram a cidade no final do século XIX e início do século XX.

A festa para celebrar o centenário foi criada com intenção de homenagear as etnias colonizadoras de Criciúma: italiana, polonesa, alemã, negra e portuguesa. Parte desta homenagem já havia sido prestada em 1966, quando se inaugurou o monumento do imigrante (ou da primeira mó), localizado na praça de mesmo nome. Naquela oportunidade, uma pedra redonda (em forma de roda de moinho), sustentada por três colunas, lembrava, simbolicamente, as três etnias fundadoras da cidade: a italiana, a polonesa e a alemã. A população negra e a litorânea (chamada de etnia portuguesa) não constaram entre as etnias. Em 1980, porém, uma nova homenagem ganha imponente edificação, e corrige falhas étnicas e históricas pela omissão de duas importantes culturas. O monumento do centenário (conhecido também como das etnias) incluía agora cinco etnias, materializadas no monumento: a italiana, a polonesa, a alemã, a negra e a portuguesa.

\section{O futuro do pretérito: um aniversário bem festejado e a etnicização celebrada}

Naquela madrugada quente, de 6 de janeiro de 1980, a cidade não iria dormir. Ao menos não uma parte dela, acostumada com os festejos daquela efeméride. Uma data a mais no calendário, mas que encerrava uma série de preparativos e discursos, diálogos, acordos, emoções. Dali a -lgum tempo, a data seria cantada pelo rei da música popular brasileira, Roberto Carlos ${ }^{4}$. Desde o dia anterior, ouvia-se pela cidade o repicar de sinos, buzinas,

\footnotetext{
${ }^{4}$ Informação obtida através de ofício encaminhado à comissão dos festejos do empresário de Roberto Carlos, acusando o recebimento do cheque de um milhão (sinal de 50\%) pago pela carbonífera metropolitana ao cantor. O show se realizou dia 29/11/1980. O contrato está disponível, na sua íntegra, na pasta de número 55 do arquivo público municipal. Sobre a contratação do cantor, uma das principais expressões musicais do Brasil naquela oportunidade, Maria Marlene Milanez Just, secretária da Educação durante as comemorações do centenário, em entrevista concedida a mim na cidade de Criciúma, comentaria: "Sabes o que era em 1980 trazer Roberto Carlos à Criciúma? Uma grande dificuldade. Partimos para algumas estratégias. A principal dela foi fazer uma espécie de jogo de egos entre as pessoas de maior posse, especialmente os empresários do carvão. Em 1980 não se tinha esta sociedade do espetáculo que se tem hoje. O patrocínio não aparecia, ao menos não de maneira explícita. Então, nós organizadores chegamos para os dois: Realdo Guglielmi e Diomicio Freitas, e dissemos que se um não trouxesse o outro traria o Roberto Carlos. Neste jogo falou mais alto o ego do Realdo Guglielmi, presidente da carbonífera Metropolitana". O show custou no total dois milhões de cruzeiros (moeda da época). Nesta época um jornal local custava 5,00 cruzeiros e uma geladeira era anunciada nas lojas da cidade por 9.590,00
} 
foguetório. A partir das $23 \mathrm{~h} 00$, um grupo de seresteiros se encarregaria da musicalidade dos festejos, que, em realidade, mais parecia uma solene celebração. Não que o povo estivesse assistindo àquilo tudo bestializado, como diriam da instalação da República brasileira, mesmo porque tudo o que estava sendo mostrado e vivido havia sido programado de longa data. Haviam sido três anos de preparação para os festejos, o tempo arranjado para dar visibilidade ao Ano 100 de Criciúma. Da Criciúma (pós)colonizada.

À zero hora do dia 6 de janeiro, dava-se início solene à celebração. O prefeito, Altair Guidi, e o presidente da comissão dos festejos, Dino Gorini, discursavam e suas falas eram transmitidas pela rádio e TV Eldorado ${ }^{5}$, de Criciúma, e pela TV Catarinense, de Florianópolis. Uma vigília nas maternidades da cidade havia sido criada para cuidar do nascimento da primeira criança do ano 100. Ela nasceria em Criciúma no décimo primeiro minutn de 6 de janeiro; uma menina, a quem foi dado o nome de Paula Regina Patrício Lino 6 .

A partida havia sido dada. Existem outras historicidades que versam ${ }^{7}$ sobre a celebração. Aqui, uma delas se inicia com um discurso fundante:

Se eu lhe disser senhor consul que aqui nesta cidade o senhor pode se sentir como se estivesse em casa, não estaria fazendo esta afirmação por mera cortesia protocolar. Pois a verdade é que esta nossa comunidade é o fruto do trabalho, do sacrifício, da perseverança e coragem de um grupo de famílias italianas que aqui vieram há quase cem anos atrás, semear nesta terra as suas esperanças. [...] Foi assim, portanto que esta cidade começou a nascer. Sem sangue, mas com suor e lágrimas. È por isto que hoje nós recordamos os passos dos imigrantes italianos, com respeito e admiração, mas também com orgulho, pois esta cidade de trabalho e progresso é o fruto daquela semeadura. E em 1980, haveremos de assinalar festivamente o centenário da colonização. Desde já criamos em Criciúma um conselho de cultura, para entre as atribuições coordenar o programa de comemorações alusivas a data, para que o esforço e a memória dos primeiros imigrantes sejam condignamente celebrados. A sua visita, Sr. Consul, configura o momento mais oportuno para convidá-lo a nos dar a honra de sua

cruzeiros. Nesta proporção, com o dinheiro gasto no show era possível a compra de aproximadamente 210 geladeiras que poderiam ajudar a resfriar um pouco o calor que fazia naquele verão de 1980. Atualmente (2013) 210 geladeiras custam em média 160 mil reais."

5 A TV Eldorado, nome da emissora de televisão local, propriedade do Grupo Freitas, à época importante grupo carbonífero da cidade, havia sido inaugurada pouco tempo antes, em 1979. Aquele era, formalmente, o primeiro evento de grande porte com o qual a TV Eldorado se envolvia.

"Realizei uma entrevista com Paula Regina Lino, que muito me ajudou a entender o "acontecido" no dia 6 de janeiro. Durante a conversa, foi possível ter uma ideia, ainda que vaga, de como era a vida de Paula Regina em 2003. Residindo na periferia do município e com uma vida de muitas dificuldades, Paula era uma das criciumenses que tentavam emigrar para os Estados Unidos em busca de "melhores oportunidades".

${ }^{7}$ Há disponíveis várias leituras sobre os festejos do centenário da colonização de Criciúma. Tal empreendimento conta com vasta documentação no Arquivo Público Municipal. Oficialmente, o que tem de mais sistematizado e publicado é ainda a obra de Arns (1985). Outras reflexões se encontram dispersas pelos jornais locais, estaduais e até mesmo na mídia nacional, em matérias pagas em revistas de circulação nacional, a exemplo da publicada na revista Veja de $1^{\circ} / 10 / 1980$, p. 106, patrocinada por empresários locais e pelo governo do estado de Santa Catarina. 
participação e apoio. Estamos ligados a generosa e a bela Itália pelas nossas próprias raízes, e é a Itália e sua brava gente que desejamos homenagear no centenário da colonização. E é a Itália, aqui tão bem representada oficialmente que em nome desta cidade desejo brindar neste momento (GUIDI apud ARQUIVO PÚBLICO MUNICIPAL PEDRO MILANEZ, 1978) ${ }^{8}$.

O texto citado é uma parte menor do discurso proferido pelo prefeito Altair Guidi em 20/5/1978, na recepção organizada pela Comissão Central dos Festejos do Centenário - CCF ${ }^{9}$ - para receber a visita do cônsul italiano em Criciúma. A celebração seria realizada para alguns poucos convidados. Antes do almoço, o prefeito ensaiava então seus passos e falas mais vigorosos. Estes passos seriam seguidos muitas vezes até o dia 6 de janeiro de 1981, data programada para o encerramento dos festejos. Isto é que era festa bem-programada! E vale dizer, desde cedo, que, com todo o incentivo dado pela prefeitura através de suas secretarias e conselhos, houve participação efetiva da população criciumense, ainda que, por vezes, de forma compulsória. Em vários ofícios encaminhados à CCF e à Secretaria Municipal de Educação (disponíveis no arquivo já citado), é possível identificar a preocupação que tinham as(os) diretoras(es) e as(os) professoras(es) de colégios do município em cumprir as determinações quanto à presença de alunos e funcionários nas celebrações programadas, especialmente durante o ano de 1980. Contudo, dado o caráter obtuso dos anos do governo João Batista Figueiredo, fica muito difícil determinar se se temia a administração municipal, à época base de apoio do governo estadual e federal, ou o medo pulsante de boa parte da população criciumense em ser alvo de repressões mais organizadas, tendo em vista que a cidade era famosa, ainda naqueles anos, por seus movimentos sociais organizados e por sua política de resistência bem viva. Não foram medidos esforços para que o ano de 1980 fosse fundante.

\footnotetext{
8 O texto, na sua íntegra, se encontra disponível no Arquivo Público Municipal Pedro Milanez, na pasta de número 59 Centenário. Até onde consegui investigar, se trata de um texto ainda não publicado, sendo ouvido apenas pelos convidados à recepção. Na mesma pasta, é possível encontrar, em folha escrita a tinta, o total das despesas envolvidas no almoço de recepção do cônsul. Foram gastos Cr\$ 6.240, , dos quais Cr\$ 4.393,00 pagos pela prefeitura, sendo o restante onerado aos 102 convidados. Criciúma foi visitada também pelo cônsul de Portugal, da Polônia e da Alemanha, sempre a convite da CCF do Centenário. A documentação disponível no Arquivo Público Municipal a este respeito é muito grande. Ofícios, cartas, congratulações confirmam com quanto afinco foram encaradas as comemorações do centenário. Ainda sobre cônsul, desta feita em relação à etnia negra, a CCF encaminhou convite, naquela oportunidade, à embaixada da Angola nos Estados Unidos. Não consegui encontrar resposta, mas é certo que o cônsul não compareceu.

${ }^{9}$ CCF: Comissão Central dos Festejos. Ainda no governo Algemiro Manique Barreto (1973-1977), foi criado o Conselho Municipal de Cultura, por sugestão de um médico da cidade, chamado José Alfredo Beirão. Tal conselho é regulamentado pela Lei n. 1.358, de 22/11/77. Até esta data, segundo o que consegui levantar, a diretoria do conselho era eleita por representantes de algumas instituições consideradas expressivas na cidade: faculdade, Rotary, colégios mais antigos. Em 1977, a Câmara Municipal escolhe entre seus membros, para indicação a ser ratificada pelo prefeito, o futuro presidente do Conselho Municipal de Cultura. Os 13 vereadores da época elegeram o historiador Mario Beloli. O conselho cria a Comissão Central dos Festejos - CCF -, em 4/5/1978 e a oficializa através do Decreto n. SE/052/79, de 16/4/1979. Os dados relativos ao centenário foram encontrados nas pastas localizadas no Arquivo Público Municipal e na entrevista concedida a mim por Mário Beloli na cidade de Criciúma, em 21-5-01. Em 1978, também será fundado o Grupo Folclórico e Artístico Seis de Janeiro, primeira dentre tantas outras entidades criadas a partir dos festejos, com a intenção de lhes dar apoio, como é possível verificar, entre outros, em A semente deu bons frutos, de Otília Arns (1985).
} 
O texto, lido na ocasião, faz uma descrição completa realizado por Demétrio Dário, incansável propugnador da conquista de novas terras, ainda na Itália, em 1879. O documento fornece uma relação de 50 famílias, oriundas de Beluno, Treviso, Udine e Vicenza, e seus nomes constam desde o recrutamento na origem até sua chegada na vila São José de Cresciúma, em 6 de janeiro de 1880. O que mais chama a atenção neste discurso é a apropriação que dele tem sido feita, pelo que se tem de indicado. $O$ texto, em realidade, é uma coletânea de informações até então dispersas: "Permita-me recordar agora, nas palavras do historiador, os primeiros passos desta gente heroica."10 A narrativa lembra Guimarães Rosa, como uma espécie de Sagarana, que será repetida durante as comemorações dos 98, 99, e dos 100 anos da colonização. Mais do que isto, em quase todas as comemorações de caráter oficial do município - desfiles de Sete de Setembro, dia da fundação (6 de janeiro) e outros tantos -, esta fala é, em alto e bom som, mostrada aos criciumenses $^{11}$. É o que chamo aqui de pedagogia da repetição, ou seria, qualificando melhr " das semelhanças? Assim mesmo, repetição que não se realiza a não ser como semelhança ${ }^{12}$ •

Maria Marlene Milanez Justi era secretária da Educação na primeira gestão de Altair Guidi. Uma administração que, segundo a própria Marlene, afinada ao que, em entrevista a mim, o prefeito mesmo diria: "para daqui vinte anos, para marcar a História de Criciúma"13. Uma das primeiras notícias que me deram os entrevistados foi que "tínhamos que conhecer nossas raízes". Outra foi a de que Criciúma era uma cidade muito "territorializada". Tinha receio e desconfiança de gente de fora. "Tanto que foi com dificuldade que implementamos o Parque Centenário. A cidade demorou a digerir a obra do Manoel Coelho, que era de Curitiba". Mas, o que fazer para sacudir a cidade? Por onde começar? Estavam no começo da gestão; era o ano de 1977. Precisavam fazer a cidade se encontrar, sair da reclusão. Desde cedo, evidentemente, as pessoas se encontravam, mas o poder público, na compreensão de seus administradores, pouco havia colaborado para que a cidade fosse "cada vez mais de todos", uma das expressões mais utilizadas na divulgação dos festejos do centenário, encontrada em quase todos os folders, cartazes e outros materiais de divulgação dos festejos.

\footnotetext{
${ }^{10} \mathrm{Em}$ realidade, não se pode afirmar quem seja o historiador mencionado pelo prefeito. Pelo que consegui investigar, trata-se de recortes e colagens, como já disse, lidos em diversas oportunidades na cidade, e que, de maneira mais organizada, estão na obra de Otília Arns, já citada.

${ }^{11}$ Como foi possível perceber na fala do locutor do desfile realizado em Sete de Setembro de 2002, quando da passagem dos grupos étnicos (que no mesmo dia estariam também na XIV Quermesse: Tradição e Cultura ou Festa das Etnias), nos alto falantes dispostos pela Av. Centenário, o discurso citado estava novamente sendo ouvido pela população e também transmitido pelas rádios locais: Hulha Negra e Eldorado. Este caráter solene e fixador também pode ser encontrado nos discursos escritos para as comemorações do centenário pelas autoridades convidadas pela comissão organizadora. É nesta dimensão que são apresentados na obra de Otilia Arns os discursos escritos, em que se fala do então presidente João Batista Figueiredo, do papa João Paulo II (em seus primeiros anos de papado), de Jorge Konder Bornhausen (governador), e do cardeal João Paulo Evaristo Arns (nascido em Forquilhinha, à época município de Criciúma, e irmão de Otilia Arns, como já dito). Para uma abordagem mais abrangente, desta feita construída sob as representações da ordem social exibida numa parada (desfile), ver Hunt (1992, p. 177-209) e também na obra Diferença e repetição, de Gilles. Deleuze, publicada in Estudos Históricos, Rio de Janeiro, v. 8, n. 15, p. 3-16, 1995.

${ }^{12}$ Ver discussão problematizadora acerca de semelhanças, diferenças e repetições, em Deleuze (1995).

${ }^{13}$ Expressão utilizada por Marlene Justi e Altair Guidi, em entrevistas que ambos me concederam na cidade de Criciúma, dias 10/3/2002 e 23/6/2000, respectivamente.
} 
Foi resolvido que uma grande festa seria realizada. Mas, por onde começar? A ocasião indicou o caminho. Comemorar os cem anos da colonização do município precisaria de uma grande estrutura: comissão organizadora, um novo paço municipal, um parque público, um hino e um monumento. Resumidamente, todos estes eventos foram levados a cabo pela CCF e também, e especialmente, pela administração Altair Guidi. Existe uma quantidade enorme de documentos no arquivo que tratam da criação dos elementos citados. A título de exemplo, foi organizado um concurso para o projeto arquitetônico do parque e para a eleição do hino.

Apesar dos esforços, e das conquistas que seriam alcançadas, era necessário despertar nas pessoas o interesse pela festa. A sedução viria de fora. Mais precisamente, de Caxias do Sul (RS). Segundo Maria Marlene Milanez Justi: "Como queríamos uma grande festa, e não achávamos nada semelhante por perto, alguém falou da festa de Caxias. Fomos em duas oportunidade para lá. Uma vez depois da festa da uva. A segunda um tempo depois."

No Arquivo Público Municipal pode-se encontrar o relatório destas visitas. Caxias do Sul estava comemorando seu centenário, o que aumentava ainda mais a importância da visita. Viajaram para essa cidade: Mario Sonego, vice-prefeito; Maria Marlene Milanez Justi, secretária de Educação, Joice Quadros, relações públicas; Nivaldo Goulart, professor da Fucri (Faculdade Criciúma). Da viagem, trouxeram boas ideias: criação de um museu. Um profissional (Vanderlei Rocha) auxiliaria na construção do Museu Augusto Casagrande de Criciúma. Realizaram uma entrevista com o coordenador geral da Festa da Uva em Caxias, Ivo Rossi, e também com seu presidente, Flavio Ioppe.

A estrutura organizacional estava idealizada após a visita a Caxias. Precisavam achar um presidente para a comissão central dos festejos. Esta seria uma tarefa difícil, pois, naquele momento, ainda segundo Marlene Justi, algumas pessoas na cidade tinham que trocar de roupa cinco vezes por dia. É isto mesmo, por estranho que pareça. A atividade de Marlene Justi não era insalubre ou danosa, mas era territorializada: "Para cada lugar que eu ia diferente, eu trocava de roupa. Eu entrevistava pessoa italianas, polonesas, alemãs, negras e portuguesas, às vezes no mesmo dia. E eu tentava então entrar no mundo daquelas pessoas, a começar pela aparência que eu daria para elas". O presidente da comissão deveria ser alguém não-envolvido, embora e necessariamente, da cidade. Não poderia ser político, tampouco alguém da prefeitura. Na tabulação, foi encontrado o dr. Dino Gorini, que havia sido médico de muitas famílias da cidade, sobretudo das assim ditas "mais importantes".

Eu, porém, gostaria de falar do acréscimo produzido - por exclusão - no depoimento de Marlene Justi, um incremento semelhante ao da tabulação pelo qual se chegou ao nome do médico. Eis que em 1980 seria comemorada também uma população que, embora viva e presente na cidade, não havia sido celebrada, muito menos com monumento. Na conta pedagógica que apresentamos no início deste texto, estávamos com três etnias (em 1966). Nas comemorações do centenário, agora, seriam cinco. A explicação para isto vem de um dos idealizadores deste incremento, o ex-prefeito Altair Guidi: 


\begin{abstract}
Nós estávamos reunidos na prefeitura, toda a Comissão. Começamos a pensar nas pessoas que precisavam ser lembradas, homenageadas. Nós queríamos uma festa para a cidade inteira, de todos. Aí começaram a listar grupos. Alguém falou dos poloneses, outro dos italianos, outro dos alemães. Eu disse: A gente tem que botar aí os negros. Esta cidade foi tocada pelos negros. E tem que colocar também os portugueses, que eu nem acho que seja português, é mais o açoriano sei lá. Os primeiros que chegaram aqui não foram os italianos. É só ver os barracões que tinha por $\mathbf{a i}^{14}$.
\end{abstract}

Chegamos, então, ao momento em que já não seriam mais três, mas cinco etnias. A comissão, porém, não queria algo somente empírico. Queriam sistematizar, deixar marcado. Neste sentido, para a comissão que organizou as comemorações, e isto fica claro tanto pelos depoimentos coletados quanto pela documentação a que tive acesso, seriam necessários profissionais muito qualificados. Foi então chamada, para organizar os dados e gerenciar as entrevistas que estavam sendo feitas a todo vapor, uma senhora de nome Otilia Arns, professora na Universidade Federal do Paraná, em Curitiba (irmã de Zilda Arns e dom Paulo Evaristo Arns) e de Bertoldo Arns, integrante da Comissão Central dos Festejos, que foi quem na verdade acabou indicando o nome dela:

Fui convidada pelo meu irmão para auxiliar na organização dos dados. Quando eu cheguei de imediato tive muita dificuldade. Depois foi se organizando melhor. Eles estavam querendo chamar grupos distintos para a festa. Eu achei que o único jeito de contar toda aquela história era falando de cada etnia. Eu já conhecia o termo. Depois então o título, que falavam sempre quando eu os encontrava: a semente, estes são os frutos da semente plantada ${ }^{15}$.

As cinco etnias estavam agora criadas, mas faltava a devida celebração. Outro curitibano (em realidade, nascido em Florianópolis) vai chegar em auxílio. Manoel Coelho havia feito arquitetura com Altair Guidi em Curitiba. "Na época eu até achava Altair vermelho", diria o arquiteto, comentando o posicionamento político de então do ex-prefeito. Experiente em administração de obras públicas, Manoel Coelho foi o "construtor" do centenário. Projetou a Avenida Centenário, que faria Fernando Carneiro, arquiteto de Criciúma, dizer: "A Centenário veio de Curitiba". De lá também teriam vindo o novo paço municipal, o Parque Centenário e o Memorial Dino Gorini, inaugurado em 6 de janeiro de 1981, portanto, um ano após o primeiro repicar dos sinos, naquele aniversário bem festejado.

\footnotetext{
${ }^{14}$ Depoimento concedido ao autor por Altair Guidi, ex-prefeito de Criciúma em 23/6/2000.

${ }^{15}$ Entrevista concedida ao autor, na cidade de Forquilhinha, por Otília Arns, em 15/3/2002.
} 
O Parque Centenário é constituído pelo Paço Municipal Marcos Rovaris, pelo teatro e a biblioteca do município, pelo ginásio de esportes e o centro, e, dividindo partes, o Memorial Dino Gorini. No arquivo público, encontra-se um documento que foi publicado também em várias edições de jornais da cidade, por ocasião dos festejos do centenário. Diz o seguinte:

\begin{abstract}
A obra dos colonizadores foi a semeadura de um amanhã melhor, conquistado com as forças de sua próprias mãos. Em meio à adversidade e desesperança, essa semente fundou raízes profundas e ergueu uma cidade sobre o solo, arrancando da terra um testemunho de luta, de perseverança e de grandeza. O que o monumento expressa é este movimento. [...] Do fundo da terra brotou um novo tempo. Do fundo da terra, somando e integrando trabalho, cinco etnias extraíram a energia que impulsionou para frente e para cima, etapa após etapa (In: ARQUIVO PÚBLICO MUNICIPAL PEDRO MILANEZ, 1978).
\end{abstract}

Fica clara a intenção de instituir e solidificar uma ideia de cidade que, mesmo expressando o "movimento" citado, guardaria as raízes. Na cidade há controvérsias quanto à leitura sobre o monumento, chamado "das etnias" pela maior parte das pessoas. Algumas dizem que o monumento representa cada uma das cinco e, mais ainda, pela "ordem presencial": italianos, alemães, poloneses, portugueses, negros. Em entrevista concedida a mim, Manoel Coelho diz:

Não pensei nisto quando fiz o projeto. Pelo contrário, queria integrar mais as pessoas. $\mathrm{O}$ monumento representa os cinco dedos das mãos, trazendo a riqueza para cidade. Pensei que isto fosse claro: a união entre o que foi agricultura e depois o carvão, construindo a cidade. Mas agora o carvão diminuiu. $O$ monumento está lá. ${ }^{16}$

O monumento está lá. Apesar de problemas como infiltração e outros, continua falando para a cidade: cinco. Se há algo positivo na valoração étnica, é bom que se diga que, pelo que pude perceber, populações antes pouco visibilizadas, ou excluídas, caso da etnia portuguesa e da negra, alcançaram visibilidade. Mas isto não significa necessariamente inclusão, uma vez que a materialidade do monumento, embora imponente, não oportunizaria real inclusão sociocultural daquelas populações na cidade.

\footnotetext{
16 Manoel Coelho se mostrou, desde meu primeiro contato com ele, um sujeito bastante disposto a ajudar. Ligou para minha casa espontaneamente ao menos duas vezes, com a intenção de falar sobre Criciúma. Passou-me fontes que foram muito úteis, tanto para mim quanto àqueles que tiverem disposição para pesquisa no Arquivo Público Municipal Pedro Milanez. Manoel Coelho me concedeu entrevista em 08/3/2002.
} 


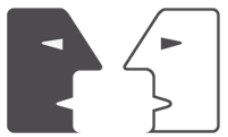

ANTÍTESES

Figura 1 - Maquete do Memorial projetado por Manoel Coelho

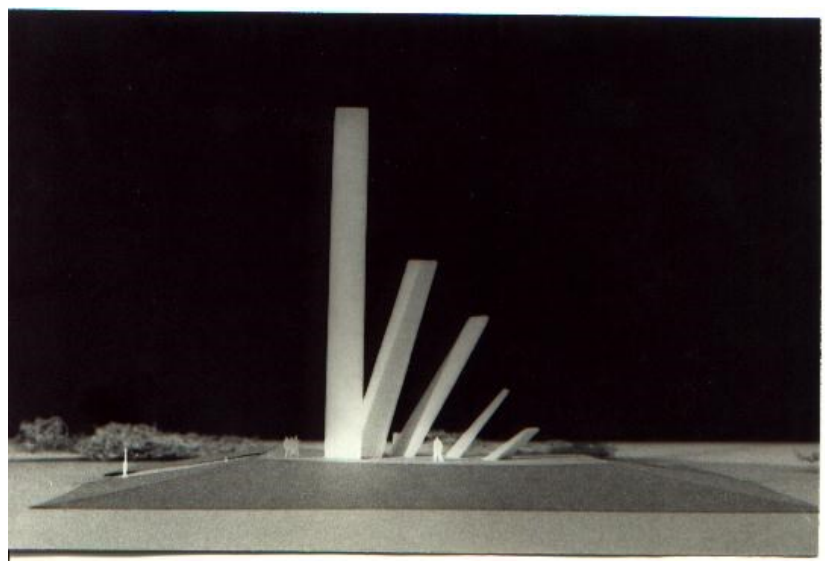

Fonte: Acervo do arquiteto cedido ao autor.

Figura 2 - Memorial Inaugurado em 06-01-1981

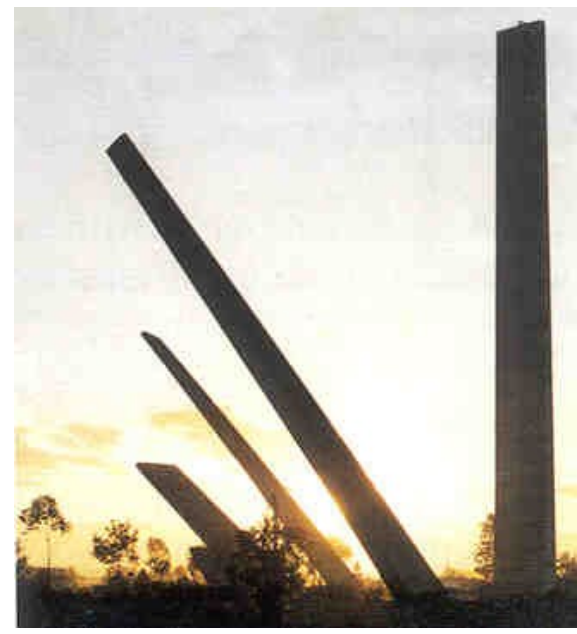

Fonte: Acervo do arquiteto cedido ao autor. 
Figura 3 - Folder- Convite "Criciúma de Todos"

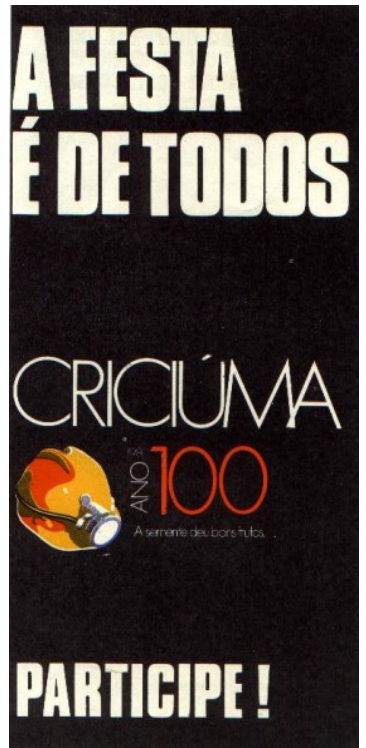

Fonte: Arquivo Público Municipal Pedro Milanez.

\section{Do preterido e não comemorado}

Uns e outros homens tiveram o desprendimento de se lançar, não à travessia do Atlântico, como fizeram portugueses, espanhóis, italianos e tantos outros conhecidos e lembrados pelo caráter civilizador, impelidos para a Terra Brasilis, mas à real aventura de transformar desvios em caminhos e, desta forma particular, integrar-se também à postura civilizadora. Os tropeiros foram, desde o século XVII até a primeira metade do século XX, homens de trânsito, embora de maneira diferente da perenidade celebrada de desbravadores da região onde se localiza Criciúma, caso dos imigrantes italianos, alemães e poloneses. Eles se preocuparam em trilhar. Isto não significa dizer que os demais civilizadores não se tenham dedicado à tarefa, mas eles, os tropeiros, deram a ela um certo estilo. Assim, parece adequado que tais homens sejam, ainda que de forma prosaica, tirados dos rodapés da história da cidade.

Ainda no império brasileiro, é certo que nos seus últimos suspiros, se implementa o surto modernizador no sul de Santa Catarina, cujo ato inaugural foi a construção da estrada de ferro Dona Tereza Cristina, em 1884. Os tropeiros, no início do século XIX, por suas andanças pelo Sul, encontraram o carvão. A notícia, rapidamente espalhada por eles, fez como que o governo imperial brasileiro deslocasse para esta região da província alguns pesquisadores para bem dar conta da fofoca gerada pelos homens de tropas. Após uma série de investidas dos pesquisadores, apenas em 1913 é que o carvão passa a ser explorado em Criciúma. 
Este caminho atravessa a cidade e, em um de seus pontos, numa comunidade dita italiana, há um memorial aos caminhadores, o qual, porém, não menciona os tropeiros. É certo que a Rota da Imigração, projeto turístico explorado pela prefeitura municipal desde 1999, é um investimento viável porque, em grande medida, carrega uma memória muar. Uma presença que se sente pela ausência: de relatos, de contos e monumentos. Uma memória que tem seus fazedores: criciumenses em geral. Contudo, sua escrita foi muito seletiva. Insisto em dizer que esta seleção não é exclusividade de um grupo específico; ela está mais conectada a um modo particular de se realizar a escrita da história, perspectiva na qual se inserem os que chamo de memorialistas-oficialistas.

A ideia de que a cidade nasce a partir de cruzamentos é relatada nos vários depoimentos que coletei. De modo voluntário e bem à vontade, as pessoas se dispuseram a falar sobre como viam a cidade, e suas referências iniciais. Entre estas, o ex-prefeito Décio Góes (20002004). Segundo suas palavras: "Criciúma nasce meio de uma encruzilhada, da estrada de ferro com as estradas de rodagem, e a partir daí cresce um comércio. Pouca gente é daqui mesmo. Daqui tem as famílias dos imigrantes italianos que vieram inicialmente. ${ }^{.17}$ Esta hibridação precoce da cidade pode ser encontrada mesmo nas obras mais tradicionais que pensam a cidade. Vejamos foto e texto que se seguem, no sentido de vislumbrar um pouco do que falo:

Figura 4 - Italianos em Criciúma, 1909

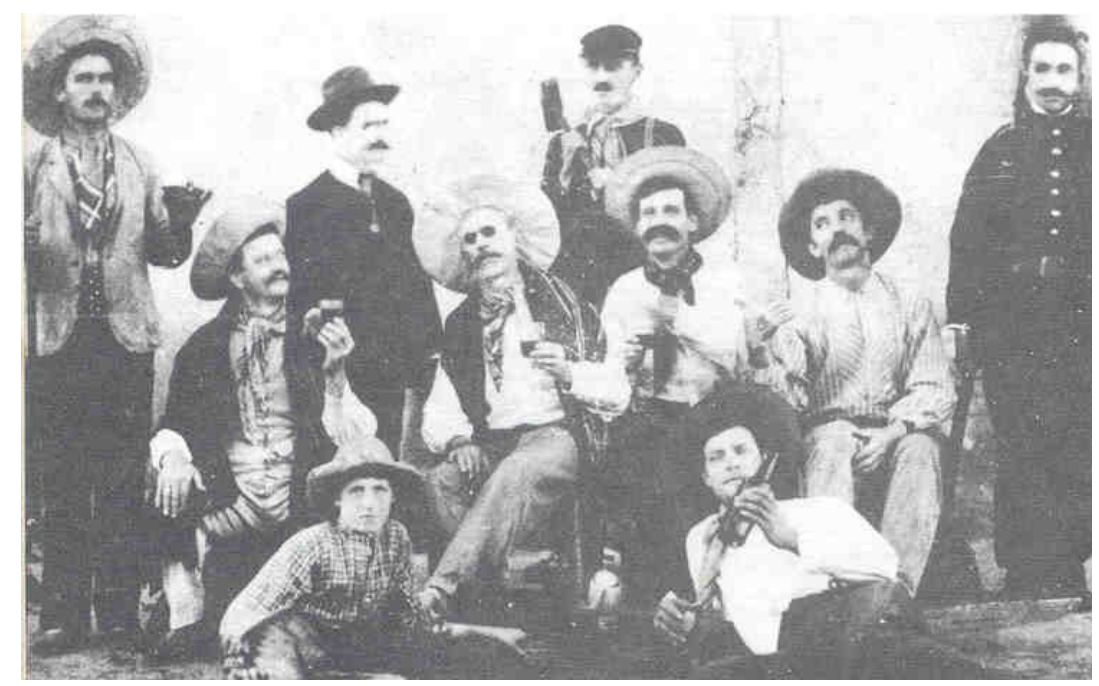

Fonte: Arns (1985, p. 50).

\footnotetext{
${ }^{17}$ Depoimento concedido ao autor, na cidade de Criciúma em 23/11/2000.
} 
Nesta imagem, ${ }^{18}$ de 1909 , os italianos, quer seja pela postura corporal ou pela vestimenta, explicitam uma gama de significados que está muito longe de indicar uma identidade acabada ou uma pureza cultural. Uma imagem que, em muito, lembra uma das inúmeras cenas de conquista do velho oeste americano. E não é a única em que estes homens aparecem desta forma.

Falemos em tropeiros. Ouvimos então a fala de um "vivente", usando a expressão do povo tropeirista, o sr. Antonio Manoel Pereira, 48 anos, residente em Criciúma. Ele se coloca como inserido numa identidade e dela excluído, ou seja, utiliza referências que momentaneamente o identificam como serrano, para logo em seguida se sentir excluído dela. O sr. Antônio Pereira é casado com uma descendente de alemães, "da cabeça bem branquinha". O que resulta é sempre algo incompleto. Estrangeiros ou bárbaros não o são por natureza. A "barbárie" é relacional, uma vez que implica uma relação com outros, uma distinção entre nós e os outros. Assim que se pode, em alguma medida, apenas entender - o que não implica admissão tácita - porque o bárbaro (ou mesmo bandido) é sempre o outro. Vejamos o que diz seu Antônio Pereira:

\begin{abstract}
Meu avô veio da serra. Não me lembro o tempo que ele nasceu (mais tarde fala em 1910). Quando chegou aqui ele casou com uma alemã, da cabeça bem branquinha. Ele veio lá de Bom Jardim. O nome dele era Serafim Pereira. Tem muito Serafim e Pereira lá para as bandas de Bom Jardim. [...]. Meu pai era um homem valente, era fogo. Até por sinal, os irmãos do meu avô, todos eles morreram matados. Só sobrou o meu avô. É uma raça muito do à toa. Até hoje os serranos são fogo, não tem moleza. É a raça mais à toa que tem. Serrano dá tapa e não quer nem saber, é na bala. Pega o 38 lá e puf! Não tem brincadeira, bobeou mata mesmo. Mas hoje eles se estabilizaram um pouco, ficaram mais quietos, na deles ${ }^{19}$.
\end{abstract}

Causa estranhamento o fato de que, ao se falar de caminhos e mesmo de tropas, os homens que se lançaram inicialmente a esta aventura não sejam lembrados. Não seria interessante uma reflexão mais elaborada a respeito? Refletir sobre monumentos que não existem, não no sentido de erguê-los - não é esta minha intenção -, mas no sentido de reconhecer esta temática como algo que possa instigar uma visibilidade e participação efetivamente maior de todos nos destinos da cidade?

Foi possível entender um pouco sobre "Pereiras e Serafins" não comemorados durante os festejos do centenário. Não enquanto "Pereiras e Serafins". Talvez o tenham sido formalmente enquanto étnicos, e daí infiro que seriam, assim, incluídos como

${ }^{18}$ Aqui e noutras partes do texto, as imagens são utilizadas de forma ilustrativa, dadas as limitações e escolhas realizadas para a escrita desta narrativa. Há forte emergência das diversas tipologias imagéticas como fontes para a pesquisa histórica, que, estruturalmente, foram preteridas nesta análise.

${ }^{19}$ Entrevista concedida ao autor, na cidade de Criciúma, em 21-6-2000. 
portugueses $^{20}$, uma etnia que, parodoxalmente, se incluiu em Criciúma por exclusão. Sigamos um pouco mais e então veremos como outras vozes foram também preteridas.

\title{
A etnicização cantada em prosa e verso
}

Durante o concurso para a escolha do Hino do Centenário de Criciúma, 52 concorrentes foram inscritos (existem outros documentos indicando 50 inscritos) e apenas uma letra e uma música selecionadas. O regulamento do concurso (disponível no Arquivo Público Municipal) prescrevia o anonimato. Neste caso, são indicados os pseudônimos utilizados por cada um dos inscritos. Gostaria de exibir todos, no sentido de sacudir a poeira que os encobre, mas não é possível assim proceder. Ficam então apenas dois deles, que, de forma rápida, tentarei mostrar. Um primeiro me chamou muito a atenção, com o pseudônimo de Juvina de Jesus, que, em um dos seus trechos, diz o seguinte:

\author{
Faz cem anos que o branco imigrante, \\ nesta terra selvagem pisou, e com a força de um bravo pioneiro uma \\ nova cidade fundou. \\ Oh Criciúma sereia morena, que nasceste no verde sertão, do teu seio \\ rojaram as minas e das minas jorrou o carvão Das itálicas plagas \\ partiram, argonautas buscando o Eldorado, \\ E aos poucos Criciúma surgiu, do trabalho de um povo arrojado. O \\ italiano, o alemão e o polaco \\ $\mathrm{O}$ africano e o luso irmanados \\ Entoaram a música rude \\ Dos engenhos, das minas e arados. \\ [...] \\ Ó Criciúma de tantos janeiros, \\ ò Criciúma no teu centenário", \\ As novéis gerações te saúdam, \\ Ó Criciúma, torrão legendário. ${ }^{21}$
}

Não foi possível identificar o autor, talvez não ainda. Sigamos. É impressionante a semelhança desta letra com a do hino vencedor do centenário, de autoria de pe. Cornélio Dall'Alba e de Sueli Mazurana, que seria cantado na cidade durante todo o ano, gravado em long play pela Associação Coral de Criciúma. Apresento apenas as partes mais interessantes, pois este é bastante conhecido:

\footnotetext{
20 Para esta "intimidade" entre a cultura brasileira e a portuguesa, ver entre outros, especialmente (RAMOS; SERPA; PAULO, 2001, p. 357-422).

${ }^{21}$ Parte da letra do hino de Juvina de Jesus. O número de inscrição do hino é o 7. Os grifos são meus, e fazem parte da discussão mais à frente.
} 
Faz cem anos que o nosso imigrante

Nesta terra selvagem pisou

E co'a força de um bravo pioneiro

Uma nova cidade fundou.

[...]

O italiano, o alemão, polonês, africano e o luso irmanados entoaram a música

Dos engenhos, das minas e arados.

Ó Criciúma de tantos janeiros.

(DALL'ALBA e MAZURANA) ${ }^{22}$

O concurso prescrevia alguns critérios: originalidade, correção e beleza de estilo, adequação para o ritmo musical, interpretação do tema histórico da colonização, correspondência ao gosto popular. Numa primeira etapa (26-9-79 a 20-10-79), houve 16 inscritos e nenhum vencedor. Numa segunda chamada (22-10-79 a 6-11-79), 52 inscritos e a indicação do vencedor, como vimos. Pois bem, Sueli Mazurana tem inscrição com outro hino (n. 25), utilizando o próprio nome. Como espécie de palimpsesto ${ }^{23}$, na letra de Juvina de Jesus foi posto o que está apresentado no hino vencedor. Disto se pode apenas inferir: ser Juvina o pseudônimo de Sueli Mazurana. Neste caso, a vencedora havia concorrido com dois hinos, o que poderia também ser possível, tendo em vista não ter havido classificados ${ }^{24}$ na primeira etapa. Acho isto menos significativo. $O$ que mais me chama a atenção é que a letra primeira de Juvina de Jesus foi visivelmente alterada para fazer ajustes musicais, mas em palavras um tanto caras à construção histórica do município. Daí o porquê de cuidar do palimpsesto. Sobre o imigrante branco, inscreveu-se o nosso; sobre o polaco, inscreveu-se o polonês. Não foi possível identificar quem fez as alterações, mas os documentos estão lá, sobrescritos desta forma. E, sobre tudo isto, os prejuízos. Acredito que o vencedor tem importância menor frente aos prejuízos.

Um outro hino bem se adapta ao critérios estabelecidos. Nele não encontrei palimpsesto, pelo menos não materializado. Ele talvez esteja inscrito no espírito. Marlene Justi, na longa conversa que teve comigo, deixou claro o ressentimento em relação aos mineradores, mais ainda ao próprio mundo do carvão. "Veja o que fizeram com a cidade. Aqui atrás da minha casa tinha um rio de águas limpas que o carvão tratou de poluir. As

\footnotetext{
${ }^{22}$ Hino vencedor, com número de inscrição 52. Autoria do padre Cornélio Dall'Alba e Sulei Mazurana. Também publicado em vários livros locais, a exemplo de Arns (1985, p. 224). Também é importante dizer que em ofício encaminhado ao dr. Dino Gorini, presidente da CCF, datado de 7/3/1980, o mesmo padre Cornélio Dall'Alba comunica que "já está encaminhando a tradução para o italiano da letra do Hino do Centenário". In: Pasta Centenário, documento protocolado sob n. 052, de 15/3/80.

23 Refiro-me aos antigos palimpsestos, nos quais os textos primitivos eram raspados para, sob o mesmo pergaminho, inserir nova escrita. A análise de palimpsestos hoje requer técnicas apuradas. O ofício do historiador não seria, entre outros, cuidar de palimpsestos? Para uma discussão sobre a artesania do oficio de historiador (que não é possível neste espaço apresentar), ver, entre outros, Albuquerque Junior (2007).

${ }^{24}$ O júri foi o seguinte: Valdenir Zannete - Cecrisa; Albertino de Oliveira - Inamps (Lauro Muller); Basílio Dalbó - Pepsi Cola; Arlindo Junkes - Colegião; Telmo Locatelli - pref. Municipal de Blumenau; irmã Verônica Weber - Laguna; Nevio Capeller - Radio Tubá, Tubarão; Dulce do Prá - Escola de Música Bella Bartok; João Kantovizk - Hosp. São José; Néri Milanez - Colégio São Bento; Flávio Vitório - Banda Cruzeiro do Sul; Jeremias F. dos Santos - Assembleia de Deus. Dados obtidos junto ao Arquivo Público Municipal.
} 
pessoas estranham a ausência dos homens do carvão no Centenário. Acho que eles se envolveram pouco mesmo." ${ }^{25}$ Observação seja feita, que em 1980 a memória do carvão ainda era muito viva, e sua ausência em lugares estabelecidos talvez se explique justamente por isto. Para lembrar Pierre Nora, quando ainda habitamos a memória, não há necessidade de lhe consagrar lugares (NORA, 1993, p. 7-28).

Entre os critérios para a escolha do hino, um estabelecia a necessidade de "interpretação do tema histórico da colonização", como vimos. Sendo assim, no próprio hino vitorioso se percebe o reconhecimento do agenciamento colonizador, não somente ao imigrante, mas também na mineração. ${ }^{26}$ Foi neste sentido que me chamou atenção a inscrição número 27.0 nome inscrito era de Edite da Silva Freitas, astuciosamente usando o pseudônimo "Dite Freitas". Ora, supondo que poucas pessoas conhecessem Edite, o mesmo não se podia dizer de "Dite Freitas", alcunha de José Francione de Freitas, que, até onde consegui investigar, não se inscreveu. $\mathrm{O}$ "Dite", famoso, foi um grande empresário em Criciúma (falecido em $7 / 2 / 2002$ ), representante do setor carbonífero. Um nome certamente a provocar ressentimentos, dado o que se sabia sobre o carvão e o que ele havia feito pela cidade. Finalizando, vejamos o que a Dite, menos conhecida, fala sobre duas colonizações; cada qual com suas pedras:

\author{
Imigrante em terras distante, \\ num país tropical veio parar. [...]. \\ Rolando pedras e moinhos, \\ do subsolo viu o carvão segregar. \\ Cortando matas abrindo caminhos, \\ a distância fazendo encurtar. \\ Criciúma centenária, \\ de povo heróico e tradição, \\ baluarte da energia, \\ és capital do carvão. \\ Unindo todas as raças \\ erguendo praças e campanário, \\ hoje canto com civismo \\ na festa do centenário

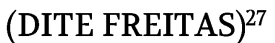

\footnotetext{
25 Maria Marlene Milanez Justi. In: Depoimento já citado. A principal ausência sentida, a dos mineradores, foi na ocorrência da Expo 100, uma grande feira industrial e comercial (realizada entre 4 e 10 de outubro de 1980), organizada para "mostrar o que faz Criciúma e o que Criciúma faz", conforme veiculado por toda a imprensa durante aquele ano e muito comentada na cidade e estado.

${ }^{26}$ É necessário dizer que boa parte dos imigrantes italianos, mais expressivos do ponto de vista econômico, também acabaram se envolvendo com a mineração. Contudo, na segunda metade do Século XX, já era bem visível a suplantação deles por homens que haviam chegado "de fora". Neste sentido, o caso mais expressivo é o da família Freitas, que chegou na cidade vinda de Orleans (SC), no início da década de 1940. Esta família foi, por mais de 40 anos, certamente o mais expressivo nome econômico de Criciúma.

${ }^{27}$ Parte da letra do hino escrito por Edite da Silva Freitas, sob o pseudônimo Dite Freitas. Inscrição N. 25. Disponível no Arquivo Público Municipal.
} 


\section{Considerações Finais}

A etnicidade hoje tem uma dimensão que se articula não somente com a de uma comunidade mais caracterizada, ou local (ou mesmo daquela politicamente imaginada); ela está também conectada a uma concepção global. Somente assim, penso, se pode afirmar que em Criciúma as etnias se "repetem". Um exemplo que pode diferenciar bem o que digo é a relação entre os festejos do centenário e outras festas, como as de Santa Bárbara e São José.

Em 1918, realiza-se a primeira festa de Santa Bárbara, no local ainda hoje chamado Mina Velha (Bairro Santo Antonio). Em 1920, constrói-se a primeira capela perto da primeira mina aberta na cidade. Desta data em diante, cresce muito o número de devotos da santa, bem como a empatia de boa parte da população criciumense envolvida com a mineração. As festas acompanham, no geral, os ritmos da indústria carbonífera. É possível dizer que a santa tenha sido a padroeira de fato do município por mais de quatro décadas. Digo, de fato, porque, de direito, o título cabia e cabe até hoje a São José. As festas de São José se iniciam em 1932. Não me parece gratuito que os encargos de organização e promoção destas duas festas - realizadas no ano de 1980 , durante as comemorações do centenário - tenham sido atribuídos aos negros e aos italianos, respectivamente ${ }^{28}$. As duas festas citadas, pelo que consegui investigar, foram desde cedo dispositivos em torno dos quais havia uma identificação mais específica de grupos sociais. A periferia e a mineração identificavam-se mais com Santa Bárbara - padroeira dos mineiros; São José, mais com o núcleo inicial, formado pelos italianos. Ambas as festas, a de Santa Bárbara e a de S. José, que, a seu modo, seguem o ritmo da vida das pessoas, hoje parecem um pouco esquecidas frente a eventosespetáculos, como a Festa das Etnias, uma tentativa de reaquecer as celebrações étnicas do centenário, criada em 1989 (na segunda administração Altair Guidi), com 22 edições já realizadas. Em realidade, as celebrações do centenário foram fundantes, como dito no início deste texto.

De modo geral, e através de vários estudos desenvolvidos (alguns aqui citados), as diferentes comunidades de imigrantes reelaboram-se a partir de velhas e novas comemorações grupais, desde a reedição de antigas festas da terra nativa até a construção de novos festejos, que tendem a consolidar uma certa unicidade do coletivo. Por outro lado, a chamada imigração histórica produziu (e produz) comemorações que ressaltam a positividade étnica e reificam o que se pode chamar de epopeia da imigração. Destacando a dureza do deslocamento e as agruras dos primeiros tempos, as terceiras e quartas gerações reforçaram o panorama de vitória conquistado pelos "pioneiros", que colaboraram fortemente na elaboração da autorrepresentação do grupo, que se entende como portador dessas qualidades. As comemorações que vêm sendo organizadas nas três últimas décadas

${ }^{28}$ Conforme documentação encontrada nas pastas do centenário no Arquivo Público Municipal. Aos poloneses coube o encargo da festa de São Cassemiro, um show artístico no estádio de futebol do atual time do Criciúma Futebol Clube, homenagens aos portugueses e a seu encargo; por último, a Festa do Colono, em Forquilhinha, ao encargo da etnia alemã. 
em torno dessa ideia de "pioneirismo" (muito presente, no caso aqui exposto, de Criciúma) acentuaram as disputas no campo da memória sobre os imigrantes no Brasil, caso flagrante entre os descendentes de italianos (mas também entre japoneses, alemães, poloneses e outros), conduzindo o trabalho dos historiadores sempre mais em direção ao estudo das narrativas mnemônicas e, também, de seus usos políticos. Assim, os lugares praticados, como nos convida a pensar Michel de Certeau - centenários, festas de família e outras -, invocam e tensionam as ideias que produzimos sobre os processos imigratórios, nos quais a etnicidade é ainda uma das mais marcadas manifestações. Esta mesma etnicidade - um fabrico, um artefato (POUTIGNAT; STREIFF-FENART, 1998, p. 49-51) -, que articula sentidos da realidade social, inventa e ficciona a nação (ou nações) e subjetiva pertencimentos, nos indica a impossibilidade de se praticar uma base étnica, seja qual for, como constituinte exclusiva da realidade sociocultural contemporânea.

Talvez este pequeno texto possa provocar outras discussões interessantes sobre processos que celebram e festejam lugares e (in)visibilizam pessoas, como se registrou no caso de Criciúma, aqui comentado. Discussões que, para além de uma polarização entre o carvão e as etnias, entre centro e periferia, entre os "da cidade" e os "forasteiros", se voltem à fluidez dos sentidos, aos entre-lugares, permitindo, assim, que vidas se instaurem num futuro aberto, e não num futuro do pretérito, ou seja, onde essas vidas simplesmente aconteçam.

\section{Referências}

ALBUQUERQUE JUNIOR, Durval Muniz de. História: a arte de inventar o passado. Bauru: Edusc, 2007.

ARNS, Otília. A semente deu bons frutos. Florianópolis: IOESC, 1985.

BURKE, Peter. (Org.). A escrita da história: novas perspectivas. São Paulo: UNESP, 1992.

DELEUZE, Gilles. Diferença e repetição. In: Estudos Históricos, Rio de Janeiro, v. 8, n. 15, p. 3$16,1995$.

FLORES, Maria Bernadete Ramos. OKTOBERFEST: turismo, festa e cultura na estação do chopp. Florianópolis: Letras Contemporâneas, 1997a.

. A Farra do boi: palavras, sentidos e ficções. Florianópolis: UFSC, 1997b.

HUNT, Lynn. A nova história cultural. São Paulo: Martins fontes, 1992.

JANCSÓ, Istvan; KANTOR, Iris. Festa, cultura e sociabilidade na América Portuguesa. São Paulo: EDUSP, 2001. 2v. 


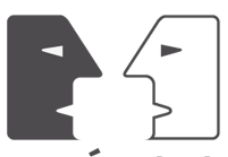

ANTÍTESES

NORA, Pierre. Entre memória e história: a problemática dos lugares. Projeto História, São Paulo, v. 10, p. 7-28, dez. 1993.

POUTIGNAT, Philippe; STREIFF-FENART, Joceline. Teorias da etnicidade: seguido de grupos étnicos e suas fronteiras de Fredrik Barth. São Paulo: UNESP, 1998.

RAMOS, Maria Bernardete; SERPA, Élio; PAULO, Heloisa. O Beijo através do atlântico: o lugar do Brasil no pan-lusitanismo. Chapecó: Argos, 2001.

TEIXEIRA, José Paulo. Os donos da cidade. Florianópolis: Insular, 1996.

VEYNE, Paul. O inventário das diferenças: história e sociologia. São Paulo: Brasiliense, 1983. 